\title{
Current and Future Applications of Transcriptomics for Discovery in CNS Disease and Injury
}

\author{
Kathryn M. Munro Victoria M. Perreau \\ Centre for Neuroscience, The University of Melbourne, Parkville, Vic., Australia
}

\section{Key Words}

Microarray · Transcriptome $\cdot$ Central nervous system Neural injury $\cdot$ Neural repair $\cdot$ Multiple sclerosis $\cdot$ Spinal cord injury $\cdot$ Traumatic brain injury

\begin{abstract}
The central nervous system (CNS) displays heterogeneity at regional, cellular and subcellular levels, making analysis of transcriptomic events accompanying neural injury particularly challenging. Microarray technology provides methods for elucidating global changes in neural gene expression and discovery of signalling pathways within this complex biological network. The lack of suitable and sufficient human CNS tissue along with its inherent variability means that diverse animal models of both multiple sclerosis and neurotrauma are vital for examining the pathophysiological changes accompanying neural injury resulting from disease or trauma. Gene expression profiling of these models is providing valuable information about mechanisms of damage, repair and regeneration and candidate treatments. In vitro models of neural injury are also proving useful, and transcriptomics is enhancing our understanding of the properties of neural stem cells with a view to their therapeutic application in neural repair. Thoughtful experimental design and analysis of microarray experiments is crucial for extracting biological meaning from the vast amount of data produced. In this review we discuss the current and emerging application of transcriptomics for the study of neural function in health, disease and injury.

Copyright $\odot 2009$ S. Karger AG, Basel
\end{abstract}

\section{Introduction}

The central nervous system (CNS), which is unique in its temporal and spatial complexity, comprises possibly the most complex system in the human body. It derives much of its complexity from multiple diverse cell types, between which a large proportion of the genome is differentially expressed (DE) [1]. The application of gene expression data to elucidate functional information from such a complex system requires elegant experimental design, generation of vast datasets and analysis tools capable of identifying biologically relevant genes or patterns from within the data.

High-throughput gene expression analysis platforms, such as microarrays, have proven to be powerful tools for generating large amounts of transcriptomic data, and have been embraced by the neurosciences as tools for elucidating function in the healthy and diseased/injured CNS.

Microarray platforms are now in common use for genome-wide analysis of expression changes in diverse experiments investigating mechanisms of neural injury and repair utilising a wide variety of models, as well as in human tissue. These approaches have yielded valuable insight into the molecular signalling pathways involved in

Gene names and symbols used were obtained from NCBI Entrez Gene and are species-specific where appropriate. Human homologues have been identified in place of salamander genes in the section entitled Spinal Cord Injury (pp 320).

\section{KARGER}

Fax +41613061234 E-Mail karger@karger.ch www.karger.com
Victoria Perreau

Centre for Neuroscience, Level 2, Alan Gilbert Building, The University of Melbourne 161 Barry Street

Carlton South, Vic. 3053 (Australia)

Tel. +61 38344 1835, Fax +61 39349 5917, E-Mail vperreau@unimelb.edu.au 
such systems. However, in addition to identifying candidate genes, microarrays and other developing technologies are revealing higher orders of complexity in the transcriptome, such as strain-dependent diversity in animal models, revealing big differences in gene expression profiling (GEP) between apparently identical cells and identifying signs of disease in apparently unaffected tissue. As the quantity and complexity of transcriptomic data increases, new analysis approaches are being applied to elucidate biological meaning from the data.

In this review, we will illustrate some of the achievements made through the application of GEP using two very different examples of neural injury: multiple sclerosis (MS) and CNS trauma (traumatic brain injury (TBI) and spinal cord injury (SCI)). Of primary importance in microarray experiments is appropriate design, including controls that provide sufficient leverage to analyse the data with the available tools. Thus, we will discuss some impor- tant design and analysis considerations, which are summarised in an experimental design flow chart (fig. 1).

Microarrays were typically applied in many studies as a primary screen or 'fishing expedition' to identify one or more DE genes for in-depth follow-up studies. Much of the early-published work was the result of diligent and often laborious analysis of lists of DE genes. Later analyses were improved upon by transcriptional profiles that allow clustering of co-regulated genes. However, these types of analysis are unsatisfactory in the face of increasing data complexity. Recent analysis approaches employing network analysis provide this now matured technology with the capacity to characterise complex gene networks in the CNS. We will discuss how methodological and analysis advances combined with neural injury models or human tissue may improve elucidation of novel signalling pathways involved in response to neural injury and regeneration.

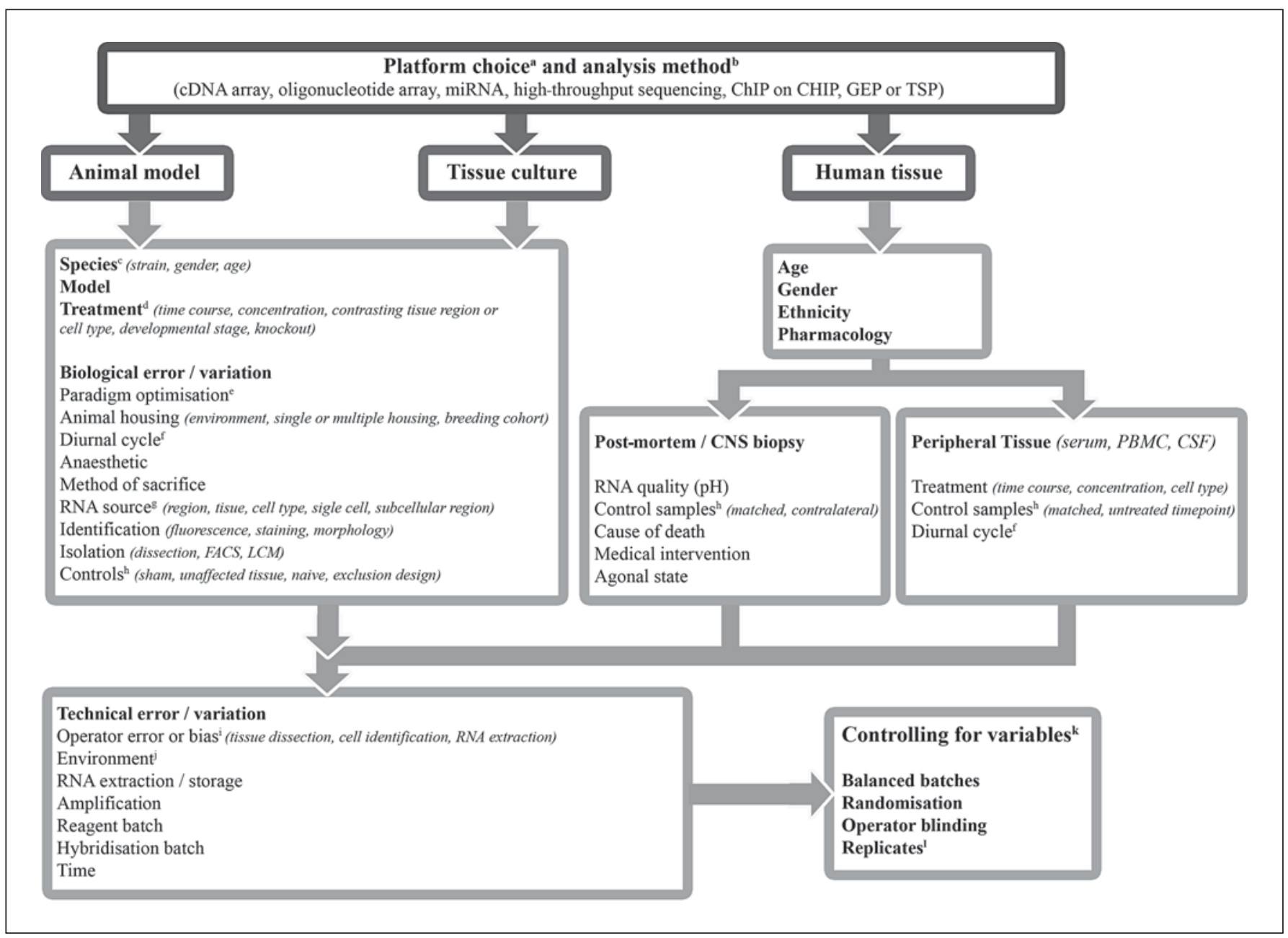




\section{Heterogeneity of the CNS}

\section{Structural and Regional Heterogeneity}

Transcriptional profiling of 20 different anatomically distinct sites across the human CNS identified both a common underlying expression signature within CNS tissues compared to tissues distinct from the CNS, as well as distinct expression signatures within each CNS region
[2]. Not unexpectedly, the cerebellum expression signature was notable for being distinct from all other CNS regions. In addition, this study identified groups of genes specific to different regions, implicating particular molecular functions in the roles of different structures. A recent transcriptome analysis of human brain, examining 3 different regions, leveraged the inherent variability in the samples from 160 individuals to identify networks
Fig. 1. Experimental design flow chart. Although not exhaustive this flow chart illustrates important factors to consider when designing a genome-wide transcriptome analysis experiment. Microarrays are very sensitive to subtle effects on global gene expression, thus the most important aspect of design is to reduce the number of variables in the dataset to a minimum and control for any sources of variation that cannot be excluded by batching and randomisation of samples.

a There are numerous platforms and suppliers, ranging from custom to genome-wide, tiling arrays and exon level arrays. Genome-wide arrays are often as affordable as smaller selected gene ones.

${ }^{\mathrm{b}}$ A detailed discussion of analysis approaches are beyond the scope of this review, however, analysis should always be discussed at the design stage as the application of analysis methods depends upon the inclusion of different treatment groups or control samples.

${ }^{\mathrm{c}}$ Different strains respond differently to treatments, a finding supported by microarray data [71].

d Treatments can be of many and multiple types, however, the analysis is always more powerful where numerous treatments are used such that profiles of gene expression across all treatments can be used to determine the direction of change and identify co-regulated genes. These could be a time course, dosage effect, different strains or genetic models, injury severity, contrasting tissues, etc.

${ }^{\mathrm{e}}$ Controlling for known variables within a treatment can decrease the variance between replicate samples and thus have a dramatic effect on the numbers of DE genes. For example, variance in models with large degrees of known biological error, such as the behavioural assessment of EAE-treated animals, can be reduced for a microarray experiment by choosing from a larger animal cohort only those animals that fall within a constrained outcome measure. Outcome measures such as RT-PCR on single genes which are markers of infection can also be used to eliminate potential biological outliers from a cohort of animals. Genes and proteins known to be important to the biological question can also be used to optimise the treatment(s) which may be most relevant to the experiment, such as choosing the best time points or dosage. Efforts spent on careful optimisation of the experimental design are well worthwhile and result in large time and money savings.

${ }^{\mathrm{f}}$ Diurnal cycle affects the expression level of a large number of transcripts. The dramatic diurnal cycling of BDNF mRNA [134] means that any of the many genes regulated by BDNF may be impacted by diurnal effect. To eliminate diurnal effect as a source of variation animal sacrifice should be constrained to within a brief defined period in a day (e.g. $2 \mathrm{~h}$ ), with treatment groups balanced within each batch if animals are sacrificed on multiple days. g In addition to how the RNA source affects the questions that can be asked of the data [see Heterogeneity of the CNS, pp 313] the quantity of RNA needed for the chosen platform and yield from biological source are both critical factors in deciding the RNA source.

${ }^{\mathrm{h}}$ Appropriate controls are an important and sometimes difficult decision. Microarray analysis findings suggest that both normal-appearing white and grey matter from affected animals or subjects may, in fact, have altered gene expression compared to normal control tissue, indicating a system-wide effect [54, 56, 135]. Additionally gene expression changes are comparable between rats given a mild contusion injury and those given a laminectomy only, emphasising the importance of including appropriate sham-operated controls rather than naïve animals in microarray studies of neurotrauma [96]. Historical controls, although attractive due to the large cost savings, introduce significant variability into a data set due to the prominent batch effect in array analysis and should thus be avoided.

${ }^{i}$ Any stage of the processing where operator error or variability could be introduced should be controlled. For example, all tissue dissections and RNA extractions should be performed by the same operator. Where bias could be introduced, such as cell selection for LCM, the operator should be blinded to the treatment groups.

j Any differences in environmental conditions whilst the cells are alive can influence variation between samples. For example, position in the incubator or time out on the bench, half life of activity of drug intervention or even any stress induced prior to animal sacrifice.

${ }^{\mathrm{k}}$ Controlling for variables in microarray experiments utilises the same principals of experimental design developed by Ronald A. Fisher on agriculture field experiments in the 1920s and 1930s. Particularly the importance of balanced blocks and randomisation to control variables.

${ }^{1}$ The old adage of biological replicates 'as many as can be afforded' still holds true. Microarray studies are almost always underpowered due to cost. However, a minimum of 3 replicates should be included in animal studies in order to execute standard statistical tests and identify single outliers, studies using human samples should include many more. The number of replicates also depends upon variance within the data, for example, older animals have more variance than young animals so experiments including cohorts of aged animals should include a greater number of biological replicates. Technical replicates, however, do not add significantly to typical array experiments as the error within the platforms is far outweighed by the biological variance. 
of co-regulated genes [3]. This study also identified consistent expression modules consistently represented across all regions in addition to some expression modules that were expressed in some but not all brain regions. As both these analyses were performed on heterogenous tissue samples, however, the transcriptional complexity produced as a result of cell type-specific gene expression within tissue regions is likely to be under-represented [see Cellular Heterogeneity, pp 314]. Consideration of these differences in regional gene expression is critical with regard to the selection of control tissues for studies involving post-mortem human samples, where uninjured matching regions may not be available [see Human Studies of Neural Disease and Injury, pp 320].

\section{Cellular Heterogeneity}

For analysis of the transcriptomic response of cell types to neural injury, one must first characterise the transcriptome in healthy cells. Although three main neural cell types are commonly discussed in the literature, neurons, oligodendrocytes and astrocytes, there are numerous additional cell types and untold numbers of neuronal cell subtypes in the CNS. Each of these cell types has a unique response to neural injury and capacity for repair. Thus, it is important to characterise the cell-specific transcriptome and response to injury.

In vitro model systems of either primary or immortalised cultures of pure, or mostly pure, cell types have provided transcriptome profiles of the main neural cell types. However, immortalised cell lines are known to behave very differently to cells in the intact animal. Even primary cultures of astrocytes, used to generate GEP, were prepared from neonatal rodent brain and possess an immature or reactive phenotype [4]. In addition to this, the molecular response of a normal cell to injury, for example, is largely governed by interactions with neighbouring cells. To complicate the matter further, many cells project long distances within the CNS; thus, cell-cell interactions can occur over great distances. Furthermore, following certain types of neural injury there is an influx of inflammatory cells, including macrophages, neutrophils, $\mathrm{B}$ and $\mathrm{T}$ cells, adding to the complexity of cell-cell interactions and molecular signalling. Thus, biological context is crucial to gaining a complete picture of the molecular response of each cell type to neural injury.

To this end, a number of different approaches have been used to characterise the expression signature of distinct neural cell types within their biological context. GEP of selected cells following fluorescence-activated cell sorting (FACS) of neuronal cell types of interest (targeted via expression of a fluorescent protein) was pioneered by Zhang et al. [5], characterising the GEP of touch receptor neurons in Caenorhabditis elegans. This methodology has been particularly successful in characterising developmental profiles of cell populations in the brain $[6,7]$ and spinal cord [8]. This approach was also used to characterise the GEP of neurons and two different populations of astrocytes from murine cortex [9]. A study of astrocytes, neurons and oligodendrocytes purified from developing and mature mouse CNS using FACS analysis provided the first cell-specific transcription profiles for all three primary neural cell types and identified thousands of new genes enriched in particular cell types [10]. The transcriptome of 12 different neuronal populations was analysed using the more gentle technique of hand sorting of fluorescently labelled neurons from defined regions in a number of transgenic mouse lines [1]. These expression signatures were used to generate a taxonomic tree that essentially recapitulated expected relationships between these neuronal subtypes and which also revealed a very high degree of heterogeneity between neuronal subtypes within the same tissue region [1]. Such discrete analyses have also been facilitated by the use of laser capture microdissection (LCM), which has been used for GEP of individual cells of different neuronal subtypes from fixed or frozen sections [11] since the earliest days of LCM technology. LCM has also been combined with a genetically targeted fluorescent label to characterise the GEP of pyramidal motor neurons and pyramidal somatosensory neurons in mouse cortex [12]. There remain some drawbacks with all of the above approaches. Both FACS and hand-sorting methods require live cell purification steps where the transcriptome may be altered in response to stimuli and LCM isolation suffers from contamination by surrounding cells. Additionally, neither sorting nor LCM would preserve neurite arbours of isolated neurons, and both dendritic and axonal processes are now known to harbour their own unique subcellular transcriptomes which respond to extracellular stimuli $[13,14]$.

Recently, isolation of RNA from genetically targeted neural cell types in vivo was made possible with the development of novel transgenic mouse strains employing translating ribosome affinity purification (TRAP) [15]. Each transgenic mouse line carries a unique bacterial artificial chromosome (BAC) targeting a specific cell type which drives an enhanced green fluorescent protein (EGFP)-L10a ribosomal transgene. The BACs were each chosen for their expression specificity from expression data from the GENSAT database [16] (http://gensat.org/). Consequently, each 'bacTRAP' mouse strain selectively 
targets a specific cell type or population that is identified by EGFP labelling. The EGFP-L10a transgene is expressed only in the targeted cells and polysomes are purified from tissue homogenates by immunoaffinity purification against EGFP. Immunohistochemistry using antibodies against EGFP can also be used to confirm cell type-specific expression in the bacTRAP mouse line. This approach thus enables the purification of cell-specific polyribosomal RNA while maintaining the vital biological context of the cell. The purified RNA can then be assayed using transcriptomic platforms to generate 'translational state profiles' (TSP). As all non-coding RNA (ncRNA) species would be excluded from the dataset, it does not technically represent the transcriptome of the cell. This methodology also overcomes the difficulty of identification and purification of rare and fragile cell types and importantly would include both axonal and dendritic polyribosomal RNA populations.

Using this approach, Doyle et al. [17] generated TSPs from 24 unique CNS cell populations and are making available 16 transgenic lines as a resource for researchers. The bacTRAP mice are a pivotal development for analysis in neurosciences as they overcome many of the design problems encountered in studies of the CNS. They can be used to assess cell-specific responses in whole animal treatments or can be crossed with knockout (KO) mice modelling human disease. In addition to increased specificity, the bacTRAP, cell-targeted TSP is also more sensitive than analysis of heterogenous tissue regions, detecting the presence of transcripts not detectable in parallel data from heterogenous tissue samples. Doyle et al. [17] calculated that for rare cell types up to $42 \%$ of genes enriched in a particular cell type may not be detected at all in microarray studies of the whole tissue region.

Elucidation of cell-specific GEPs via the above approaches is sure to reveal yet more complexity within CNS transcriptomes; they have already shown that the diversity among neuronal subtypes is comparable to that between neurons and glia [17]. Interestingly, the genes with the most variable expression between different cell types are predominantly expressed at the cell surface or are involved in synaptic connectivity $[1,17]$, supporting the concept that cell-cell communication drives function within the CNS.

Approaches have also been incorporated into GEP analysis methods to account for the varying proportions of different cell types in microarray data from heterogenous tissue. One approach generated ratios of gene transcript levels between grey matter and adjacent white matter samples to estimate the relative cellular origins of gene expression. Lists of white or grey matter-enhanced genes could then be removed from the analysis, post-hoc, to focus the list of DE genes from cell types predominantly in white or grey matter [18]. Although these analyses were executed without imposing any a priori assumption on the expression pattern of any genes, many genes are commonly expressed in multiple cell types to different degrees. Thus, significant aspects of signalling pathways could be overlooked with this approach. An improved approach has applied network analysis to transcriptome data from 160 human brain control samples and generated modules of co-expressed genes that correlate with neurons, oligodendrocytes and astrocytes [3], [see Conclusions and Future Directions, pp 323].

\section{Single-Cell Transcriptomes Hint at Higher Levels of Complexity}

Single-cell analysis has been a long-held aim of neuroscientists, and consequently much of the early literature on single-cell transcriptomics relate to the neurosciences. This desire is driven by the need to reveal the behaviour of single cells within the cellular heterogeneity of the CNS. The early uptake of this challenge combined a variety of methods for isolating mRNA from single cells, followed by amplification techniques and combined with microarray analysis [for review, see 19]. For methodological concerns for the application of single-cell transcriptomics to TBI, see Davis et al. [20].

A key finding from single-cell GEP in the CNS and other tissues is the degree of variation between neighbouring, apparently identical cells. LCM of 14 pyramidal neurons from the CAl region of the rat hippocampus demonstrated a large degree of variation in the transcriptome of neighbouring cells which were apparently identical [21]. LCM was subsequently used to isolate fluorojade-labelled neurons in a rat TBI model, where the expression of the neuroprotective genes, glutathione peroxidase 1 , heme oxygenase 1 , and brain-derived neurotrophic factor, were found to be significantly decreased in injured CA3 neurons compared with adjacent uninjured neurons [22], demonstrating that transcription signatures of adjacent neurons vary greatly depending upon survival. This variation does not appear to be due to technical noise, suggesting that cellular systems are inherently noisy at the single-cell level [23]. Using murine neural stem cells (NSCs), Subkhankulova et al. [23] determined that the majority of transcripts (44\%) are present at less than 25 copies/cell and proposed that this low abundance along with translational regulation may account for the observed heterogeneity. 


\section{RNA Transcript Populations in Subcellular \\ Compartments}

Subcellular mRNA localisation and local translation enables the generation of protein gradients which are essential for cell polarity [24]. Localised protein translation within neurons has been known for some time, and recently a small number of groups overcame technical difficulties to characterise some populations of localised transcripts. Subcellular fractionation methods combined with microarrays were used to characterise transcripts that are localised to RNA granules [25], the synaptosome $[25,26]$, synaptoneurosomes [26] and postsynaptic density fractions [26, 27]. Microarray analysis has been successfully used on axonal RNA isolated from in vitro cultures using microfluidic chambers [13] or size exclusion membranes [14]. These studies found a diverse range of transcripts in all subcellular populations. Additionally, some populations were shown to respond dramatically to injury $[13,14]$, neurotrophin treatment $[14]$ or neural activity [25]. An abundance of transcripts for ribosomal subunits were also detected in both dendritic [25] and axonal preparations [13], suggestive of a dynamic capacity to increase translation rates at sites of local protein synthesis. It is important to note that polysomal fractions report TSP as apposed to GEP and RNA granules are sites of RNA silencing; thus, changes in the mRNA profile following neural activity indicate translational repression in dendrites [25].

There remains scope for further elucidation of the regulation of RNA subcellular localisation within neural cells by comparing transcript profiles from different polysomal fractions. The transcript signatures from cytosolic and membrane-bound polysomal fractions have been successfully compared in Hela cells [28]. However, a third polysomal fraction, associated with the cytoskeleton and involved in translation of specific RNA species [29], has not yet been examined. Annexin 2 protein is specifically associated with only these cytoskeletal-bound polyribosomes [30] leading to the possibility that immunopurification could be utilised to isolate cytoskeletalbound polysomes and their associated transcripts. Additionally, RNA-binding proteins are involved in the localisation of transcripts and microarray analysis has shown that they are associated with specific sets of functionally related transcripts, implicated then in the regulatory control of local translation [31-33].

\section{Transcriptome Complexity}

The presence of ncRNAs in the cellular transcriptome is of increasing relevance. The importance of ncRNA in the CNS was elegantly illustrated by a project that exclusively used expression data from the Allen Brain Atlas to characterise expression profiles of 1,328 transcripts [34]. They found that $64 \%$ of the ncRNA transcripts they examined were expressed in the adult mouse brain and the majority of ncRNAs were associated with specific neuroanatomical regions, cell types and compartments. Importantly, when the expression patterns of ncRNA were compared with the associated coding genes, many ncRNA expression patterns overlapped with important CNScoding genes. MicroRNAs (miRNAs) are 22 nucleotide endogenous ncRNAs that post-transcriptionally repress protein-coding genes by base-pairing to 3' UTR; at the time of writing, the mouse miRNA database [35] (http:// microrna.sanger.ac.uk) contains 9,539 transcripts. Bak et al. [36] profiled expression of all miRNAs in 13 different CNS areas and found that 44 miRNAs displayed threefold enrichment in at least one area. In addition, $50 \%$ of miRNAs exhibited different CNS expression patterns compared to zebrafish, demonstrating divergent expression across species.

\section{Animal Models of Multiple Sclerosis}

MS is a central demyelinating disease resulting in oligodendrocyte death and axonal injury, with an associated progressive and irreversible neurological decline [37]. Its cause is unclear; however, it is generally accepted to be an autoimmune disease involving chronic inflammatory demyelination, and numerous genetic and environmental factors have been implicated in the aetiology of MS [for review, see 38]. The pathophysiology of MS involves oligodendrocyte apoptosis, infiltration of $\mathrm{T}$ cells, destruction of myelin by macrophages $[39,40]$, gliosis and axonal damage [41]. While the cause of the immune-mediated myelin destruction is a source of debate [42], it is believed by many to involve the activation of self-reactive $\mathrm{T}$ cells specific for myelin antigens. The course of the disease is variable and presents clinically in several forms: relapsing-remitting, secondary progressive, and primary progressive. Furthermore, inflammatory lesions appearing in the brain and spinal cord are classified into different subtypes based on their pattern of demyelination, suggesting that multiple mechanisms are responsible for demyelination [39, 43]. Transcriptomics has been widely used to investigate this heterogenous and complex disease through the use of both animal models and studies using patient samples [see Multiple Sclerosis, pp 320]. 


\section{EAE and Cuprizone Models of Multiple Sclerosis}

While there are no animal models that perfectly reproduce this complicated disease [40], two models have been extensively used to examine particular features of the disease and utilised in a number of microarray experiments: experimental autoimmune encephalomyelitis (EAE) and cuprizone intoxication. The pathological features of both EAE and cuprizone vary according to the species, strain and antigen used [44, 45]; gender and age also influence the response to cuprizone $[45,46]$.

EAE is a model of CNS inflammatory demyelination, induced by inoculation with various CNS myelin antigens or passive transfer of myelin-specific $\mathrm{T}$ cells. $\mathrm{Al}$ though an imperfect model of human MS it shares numerous features such as the presence of multiple inflammatory CNS lesions, making it a useful model for MS research [for review, see 44]. Additionally, clinical disease symptoms such as ascending hindlimb paralysis vary between models, and can have progressive or relapsing-remitting patterns [44]. Over the last decade numerous microarray studies have utilised EAE models with a number of aims; Comabella and Martin [47] reviewed the data up to 2006. Early transcriptome studies identified DE genes associated with EAE progression, constructing a comprehensive profile of the molecular changes occurring in each stage of the disease [48] and identifying genes which may contribute to CNS repair [49]. Other studies analysed the action of potential therapies [50] and identified common DE genes between EAE tissue and human MS lesions [51]. More recent microarray analyses, described below, have continued to augment our understanding of the pathophysiology of EAE.

A temporal profile of $\mathrm{DE}$ genes in a relapsing-remitting rat EAE model revealed altered pathways (cholesterol), identified likely pro-regenerative genes, and discovered a highly DE gene (secretory leukocyte peptidase inhibitor, SLPI, ID 84386) previously un-associated with EAE [52]. To assist their analysis, in addition to comparison of gene expression in healthy and affected diseased spinal cords, the authors subtracted genes that were DE in healthy rat lymph nodes thus filtering out $\mathrm{DE}$ genes from non-activated infiltrating leukocytes and adding more power to their dataset. They identified that genes involved in the cholesterol biosynthesis pathway were downregulated in all stages of disease; however, genes involved in cholesterol transport were unaltered. Further experiments found no difference in the total cholesterol concentration in spinal cords from control and EAE-affected rats leading the authors to suggest the involvement of a negative feedback loop. This model also enabled the authors to identify a small number of likely pro-regenerative genes that were upregulated in the spinal cord during the recovery phase but not the attack phases. Some genes, such as microtubule-associated protein 2 , had previously been associated with CNS repair while other novel genes had not. Finally, expression of secretory leukocyte peptidase inhibitor was upregulated 100 -fold in the acute phase and 10-fold in other phases of the disease; protein localisation and in vitro experiments suggested a role in modulation of the immune response and promotion of CNS repair.

$\mathrm{KO}$ mice have previously been utilised to investigate genes influencing EAE development and progression [51, 53]. In an effort to identify pathways promoting remyelination, a recent study by Cudrici et al. [53] compared GEPs from the spinal cords of mice deficient in complement component $\mathrm{C} 5$, which display severe gliosis and axonal degeneration during chronic EAE, to mice sufficient in $\mathrm{C} 5$, which in contrast display extensive remyelination. Genes involved in the insulin-like growth factor and transforming growth factor families were $\mathrm{DE}$, indicating a role of these genes in the detrimental phenotype seen in C5-deficient mice and providing potential future therapeutic targets.

Transcriptomics has identified gene expression changes in cortical grey matter distant from lesions that appeared histologically normal [54]. Microarray analysis of normal-appearing grey matter in the cortex of EAE-affected rats identified numerous DE genes, particularly downregulation of genes encoding mitochondrial proteins; this may be a result of neurodegeneration in the spinal cord [54]. Transcriptional changes in normal-appearing white matter have been demonstrated in the post-mortem brains of human MS patients [55, 56; see Human Studies of Neural Disease and Injury, pp 320]; however, this finding was not recapitulated in an EAE study [54], illustrating the differences that may be seen between human MS and its animal models.

Another widely used animal model of MS is the cuprizone intoxication model [for review, see 57, 58]. Ingestion of the copper chelator cuprizone leads to demyelination of various brain regions, particularly the corpus callosum which presents with a rostral-caudal gradient of pathology [59]. An inflammatory response involving activated microglia and macrophages accompanies the demyelination [60], but in contrast to EAE, there is no disruption to the blood-brain barrier or T-cell infiltration. Importantly, the demyelinating effect of cuprizone is reversible and withdrawal of cuprizone treatment results in spontaneous, progressive remyelination. 
Microarray studies have therefore utilised the cuprizone model in an attempt to identify genes and pathways which may be modulated to prevent demyelination and stimulate remyelination after injury, thus protecting the axon [61]. Therefore, the inclusion of multiple time points within experiments is of pivotal importance as genes will be decreasing or increasing depending on the stage of disease. Additionally, some spontaneous remyelination is seen at $\sim 6$ weeks despite ongoing cuprizone treatment. This is likely to be due to the proliferation of oligodendrocyte progenitor cells [57].

Studies have examined gene expression changes occurring during cuprizone treatment in vivo, identifying alterations in the expression of genes associated with myelin and inflammation as well as genes associated with diverse functions such as cell signalling and transcription $[62,63]$. Microarray results from the cuprizone study by Arnett et al. [63] led to the further characterisation of p8 (also known as nuclear protein 1, ID 56312), a stressassociated gene upregulated during demyelination but not remyelination [64]. Experiments with p8 KO mice confirmed the role of this gene in the exacerbation of demyelination and inflammation; additionally, p8 upregulation was identified in EAE tissue and post-mortem brain tissue from MS patients [64].

The cuprizone model has been employed in combination with transgenic mice to examine the contribution of particular genes to remyelination. Li et al. [65] used microarrays to support their analysis of the role of $\mathrm{p} 53$, a pro-apoptotic transcription factor upregulated in the corpus callosum of cuprizone-treated mice. p53 KO mice and mice treated with a 53 inhibitor displayed decreased demyelination and less recruitment of microglia than wild-type (WT) mice; this was reflected in the results of the microarray which revealed higher expression levels of myelin genes and decreased levels of genes related to macrophage and microglial function and cytokine function. Arnett et al. [63] compared gene expression changes in the corpus callosum of WT and tumour necrosis factor- $\alpha \mathrm{KO}$ mice, known to have a decreased capacity for remyelination after cuprizone exposure, to identify DE genes in the remyelinating phase which may contribute to this lack of repair. DE genes were associated with cell signalling, transcription and the cell cycle, and the largest category was related to inflammation and the immune response. Genes in the major histocompatibility complex were downregulated in tumour necrosis factor- $\alpha \mathrm{KO}$ compared to WT mice during the remyelinating phase, and further experiments confirmed the upregulation of major histocompatibility complex II following cuprizone treatment affected oligodendrocyte regeneration and the rate of remyelination.

\section{Animal Models of Traumatic Brain Injury and Spinal Cord Injury}

The pathology of human TBI and SCI is complex, and varies depending on the type and severity of injury. The initial trauma sets in motion a variety of events which lead to further damage. Well-characterised components of neurotrauma include blood-brain barrier disruption, infiltration of inflammatory cells, astrogliosis and glial scar formation, excitotoxicity, cell death and axonal degeneration; tissue atrophy may continue many months after the injury [for review, see 66]. As well as the focal area of damage caused by TBI, the mechanical force of injury itself can disrupt axonal membranes resulting in axonal injury and affecting the survival of neurons [67].

As described for MS, microarray studies attempting to elucidate the molecular responses to neurotrauma have utilised a range of animal models. Commonly used models of TBI include controlled cortical impact, weight drop, impact acceleration and fluid percussion [for review, see 68]. These models result in focal injury (cortical controlled impact, weight drop), diffuse injury (impact acceleration) or a combination (fluid percussion). Another model of TBI, cryoinjury, involves application of dry ice to the skull. Similarly, different SCI animal models are utilised; while a crush or contusion model of injury most accurately resembles human SCI, trans-section models can reliably sever spinal cord axons and provide an accurate evaluation of axonal regeneration [69]. Transcriptome studies are affected by the species, strain and model of neurotrauma used and are thus an important consideration for design (fig. 1). General differences in rat and mouse SCI models include the formation of either a cavity (rats) or fibrosis (mice) at the lesion centre, and differences in the inflammatory response [70]. Strain differences were demonstrated in a microarray study comparing the response to contusion injury in three common strains of rat which exhibited different functional outcomes [71]. The genetic background of rodents can affect the extent of neural regeneration [72] and wound healing [73]. However, different strains cannot simply be presumed to have a significant difference in GEP after injury; a study comparing two rat strains known to have different inflammatory and recovery responses after contusion found a relatively small number of DE genes 
between them over an extended period of time after injury, emphasising the fact that regulation of transcript levels are only a small part of regulatory responses following injury [74].

\section{Traumatic Brain Injury}

The early uptake of microarray technology led to significant advancements in the understanding of the molecular cascades initiated following TBI [for review, see $75,76]$. These studies have identified numerous variables that have large effects on the molecular responses to injury. Cumulatively, these studies have examined the general pathological and protective mechanisms involved in primary and secondary injury [77]; determined how different areas of the brain including the cortex [78-80], hippocampus $[81,82]$ and subventricular zone (SVZ) [83] respond to TBI, and discovered differential gene expression as a consequence of injury severity [84]. Despite the differences expected between strains and models of TBI, the alteration of many genes after injury has been shown to be consistent [85]. The temporal effects on molecular changes following injury have been examined in countless studies. Temporal delays in gene expression changes can occur; conversely, altered genes, including transcription factors whose expression is induced minutes or hours after injury, may return to control levels within $24 \mathrm{~h}$ [76]. Hierarchical clustering of genes with similar expression patterns after injury - particularly at different time points after injury - is helpful for determining common pathways or upstream regulators that contribute to the change in transcription [76].

As in MS studies, transgenic mouse lines have been utilised to examine the impact of particular genes on the global response to TBI. Two studies have examined the transcriptome response to cryolesion in mice which have altered levels of the cytokine interleukin-6 (IL-6), an inflammatory mediator known to have significant and wide-ranging effects on the response to neurotrauma. The first used IL- $6 \mathrm{KO}$ mice which have a worse than usual response to TBI [86], and the second used transgenic mice which produce IL-6 in astrocytes and are known to have less cell death and increased repair after TBI [87]. IL-6 KO mice had a substantially different response at 1 day after injury compared to WT controls, with a tendency for attenuated upregulation of multiple transcription factors; the authors suggest it is this early transcriptional difference that underscores the later poor recovery from TBI [86]. Mice producing IL-6 in astrocytes had increased expression of inflammatory genes compared to WT controls, as expected; they also had de- creased expression of pro-apoptotic genes and changes in genes associated with a wide range of processes including oxidative stress, synaptic activity, and cell migration and proliferation [87], thus demonstrating the pervasive nature of IL-6 signalling following injury. In another example, recent studies have conducted microarray analyses of TBI using mouse models of Alzheimer's disease [ 88 , 89]. In one study [89], mice expressing the human apolipoprotein E (APOE) gene isoform APOE4, previously associated with a poorer outcome after TBI, were compared with APOE3 mice 4 weeks after receiving a controlled cortical impact. APOE4 mice had far fewer DE genes in the hippocampus and cortex compared to APOE 3 mice at this time point. Fewer genes associated with the immune response, cellular movement and cell-cell signalling and interaction were observed in the APOE4 mice, among other categories. This led the authors to suggest that APOE4 mice fared worse after TBI because of the gene expression changes and post-injury mechanisms they were lacking, and not because of increased neurodegenerative mechanisms as had been expected, thus illustrating the advantage of observing global gene expression changes with microarray technology.

There are currently no effective therapeutic treatments for TBI; however, the efficacies of candidate therapies are being tested in vivo and GEP is assisting in revealing their mechanism of action. FG loop (FGL) is a peptide derived from the neural cell adhesion molecule that is neuroprotective in an ischemic model of TBI [90] and induces neurite outgrowth in vitro [91]. Pedersen et al. [92] examined the effect of FGL treatment of cryolesioned rats using GEP across 2 time points and identified 4 clusters of genes responsive to the interaction effect of FGL and TBI. These clusters indicated involvement of diverse pathways implicated the Fas apoptotic inhibitory molecule (FAIM, ID 140930) in the neuroprotective contribution of FGL. Minocycline is an anti-inflammatory agent that reduces the volume of secondary injury $24 \mathrm{~h}$ after lesion and is currently of interest as a potential neuroprotective treatment; however, the biological processes it acts upon are unknown. Crack et al. [93] administered minocycline to mice injured using a weight drop model. They identified potential effects of minocycline on a large number of diverse pathways including astrogliosis. They also, unexpectedly, found that in TBI minocycline upregulated the pro-apoptotic genes caspase-3 (CASP3, ID 12367) and caspase-8 (CASP8, ID 12370), implicating minocycline in activation of cell death pathways. This study also revealed the involvement of many more inflammatory molecules in TBI than previously supposed. 
A recent study examined changes to miRNA expression in rat hippocampus after controlled cortical impact detected alterations in 85 of 444 miRNAs examined [94]. These transcripts were predicted to target a wide variety of genes involved in general and essential roles such as transcription, signal transduction and proliferation. The discovery that DE miRNAs are part of the transcriptome response to TBI adds an additional layer of complexity to GEP and has huge implications for our understanding of the events underlying neural injury.

\section{Spinal Cord Injury}

Aimone et al. [95] conducted a comprehensive study of gene expression following a rat contusion injury. They examined gene expression changes in the lesion epicentre as well as in the spinal cord both rostral and caudal to the lesion site. Multiple time points (up to 35 days after injury) were examined and importantly included both laminectomy and naive controls. Unusually, four different analysis methods were applied in an effort to eliminate bias generated through statistical assumptions. This multidimensional experiment demonstrated the temporal and spatial complexity of gene expression changes and identified affected regulatory pathways in multiple affected systems, including: inflammation, complement cascade, vasculature and angiogenesis, cholesterol biosynthesis, cell death, calcium signalling, and synaptic plasticity. A subsequent study by De Biase et al. [96] additionally examined the effects of mild, moderate and severe contusion. They showed that gene expression responses following mild injury were relatively rapid, whereas they were delayed and prolonged after severe injury.

The ultimate aim of SCI research is neural regeneration leading to functional recovery. Microarray technology is being applied to different models of neural regeneration including in vitro models of neurite outgrowth [97], and in vivo analyses of injury in the peripheral nervous system, where repair can occur $[98,99]$. Identification of conserved genes which are similarly or differently expressed after injury in regenerating compared to non-regenerating animals may help elucidate genes important to this response; thus, animals that naturally exhibit CNS regeneration after injury, such as the immature Monodelphis domestica [100] and salamander [101], are therefore of particular interest. Such approaches are illustrated by a study using a small-scale array of inflammatory genes implicating them in the regenerative capacity of $M$. domestica [100]. Monaghan et al. [101] used a custom-made microarray chip to examine early gene expression changes following SCI in salamanders, which display regeneration and functional recovery after tail amputation. Numerous genes known to be upregulated in mammals after injury were similarly upregulated in the salamander, including jun B proto-ocogene (JUNB, ID 3726), APOE (ID 107741), heme oxygenase 1 (HMOX1, ID 3162), and genes involved in the immune response. Conversely, several genes associated with glutamate metabolism and transport were downregulated in the salamander after injury, contrary to the response expected in mammals. Mona-ghan et al. [101] compared their gene list with previously published rat SCI studies; several genes DE in the salamander only had previously been linked to injury in other regenerating animals (e.g. amphibians). The use of such models for transcriptomics has been limited until recently due to the availability of species-specific arrays; however, the advent of highthroughput sequencing will enable further studies to be undertaken.

\section{Human Studies of Neural Disease and Injury}

In addition to the heterogeneity of MS and neurotrauma, gene expression changes in the human brain are also dependent on both age and gender [102]. The tissues available for microarray analysis include post-mortem CNS tissue (or brain biopsy tissue in a small number of cases), cerebrospinal fluid and blood.

\section{Multiple Sclerosis}

As mentioned in Animal Models of Multiple Sclerosis [pp 316], MS is a complex neural disease with different clinical forms, and transcriptomic research approaches were embraced with the hope of identifying factors influencing disease susceptibility. Early studies indicated a significant genetic factor in susceptibility to disease, and thus both large genotype studies and expression profiling studies have been conducted in efforts to elucidate the genes affected. Microarray studies relating to MS are diverse and pose a variety of biological and clinical questions. Studies using tissues such as peripheral blood mononuclear cells aim to identify biomarkers to aid diagnosis, predict disease course and examine patient responses to treatment. Analysis of peripheral blood mononuclear cells is particularly popular for research into MS; however, as it does not directly relate to neural injury, it is not discussed here. Post-mortem brain tissue has been used to identify molecular changes in healthy versus diseased tissue, and has de- 
tected DE genes in lesions classified as acute, chronic active and chronic inactive [103-105].

Gene expression analysis has identified mitochondrial dysfunction as a contributing factor to the pathogenesis of MS [106]. Dutta et al. [106] compared non-lesioned motor cortex tissue from MS patients with severe disabilities to tissue from matched controls without neurological disease. DE genes were associated with processes including oxidative phosphorylation, synaptic transmission and cellular transport. Notably, 26 genes associated with the mitochondrial electron transport chain were downregulated in the motor cortex of MS patients. Further experiments confirmed that the function of mitochondrial respiratory chain complexes I and III were reduced in MS patients.

Expression profiling studies comparing normal-appearing white matter from MS patients to controls have identified gene expression differences in seemingly healthy tissue adjacent to areas of damage $[55,56]$. Zeis et al. [56] found upregulation of genes within the JAK-STAT signalling pathway in normal-appearing white matter from MS patients, a pathway linked to immune regulation. Further experiments confirmed that the protein products of anti-inflammatory genes, signal transducer and activator of transcription 6, IL-4 induced (STAT6, ID 6778) and Janus kinase 1 (JAK1, ID 3716) were predominantly localised in oligodendrocytes, and the protein product of the pro-inflammatory gene signal transducer and activator of transcription 4 (STAT4, ID 6775) was localised to microglia and some astrocytes in normal-appearing white matter, leading them to hypothesise that upregulation of anti-inflammatory genes in oligodendrocytes contribute to the protection of normal-appearing white matter in MS patients. This study demonstrates that apparently unaffected tissue in the same individual may not in fact be a suitable normal control.

\section{Neurotrauma}

Typical microarray analyses are very sensitive to uncontrolled variables within sample sets. Thus the variables accompanying TBI, combined with the difficulty of obtaining sufficient numbers of characterised human samples, has impeded the use of transcriptomics on human samples to such a degree that to our knowledge there is only one transcriptomic study using multiple human brain samples following TBI [107]. This study, on 7 patients, serves to exemplify many of the problems encountered when controlling for variables in human TBI, including age, gender, ethnicity, type and severity of injury, time elapsed since injury, pharmacological intervention, alcohol consumption, anaesthetics, and appropriate control samples. The same concerns relate to studies on spinal cord tissue from human SCI patients for which no transcriptomic studies could be identified.

\section{Employing Stem Cells in Neural Regeneration}

Stem cells and progenitor cells are areas of intense research as potential therapeutics for neural repair [for review, see 108]. Stem cells can give rise to neural progenitor and neural precursor cells, which can be manipulated in vitro and grafted into the injured CNS. Consequently, implanted NSCs are being investigated for their capacity to replace missing and damaged cells [109]. It is also envisaged that the migratory properties of NSCs may make them suitable vehicles for gene therapy delivery [110] and that neurogenesis within endogenous adult NSC populations could be manipulated to assist repair and regeneration of the CNS [111]. GEP is enabling a better understanding of stem and progenitor cell differentiation, accurate staging and identification of cell lines, and addressing some of the fundamental questions in NSC biology that need to be answered before such approaches can be realised. Genes, proteins and signalling pathways involved in stages of cell differentiation are being defined in vitro, as well as how these characteristics can be manipulated by cell culture conditions $[112,113]$. Examples of recent studies are described below.

Numerous studies have used microarrays to examine the changes in gene expression as NSCs go through stages of differentiation [112, 114-116]. Cai et al. [112] looked at the in vitro method of 'priming' cultured human NSCs, which causes the cells to differentiate into neurons (rather than astrocytes) when grafted into the adult CNS [117]. To examine how neural priming varied from the normal process of neural differentiation, they first compared primed and unprimed cells at various time points, before going on to compare unprimed, differentiated human NSCs with cells that had first been primed and then differentiated. This enabled them to identify the altered genes and pathways which ultimately led to a different cell phenotype (these included Notch, Wnt, and trimeric $G$ protein pathways) and provided valuable information about the mechanisms involved in the priming and differentiation of human NSCs in vitro, and how to direct NSCs to differentiate into neurons after implantation.

Obayashi et al. [113] used microarray technology to address the issue of neural progenitor cells differentiating into astrocytes following implantation in the CNS, an 
unwanted outcome which may contribute to astrogliosis. They examined gene expression differences in human neural progenitor cells cultured with and without serum conditions known to promote astrocyte differentiation. Analysis of relevant genes combined with further experiments enabled them to identify a component of the serum, BMP4, which is likely to play a major role in inducing astrocyte differentiation. The gene expression data also allowed them to form a hypothesis about the gene interactions that leads to BMP4 induction of astrocyte differentiation.

GEP has been used to characterise a common stem cell gene expression signature within stem cells from lateral ventricle wall tissue, neurospheres and another stem cell line [118]. Conversely, GEP has also shown that phenotypically identical NSCs may, in fact, differ in their GEPs. This finding is supported by transcriptomic data from Kelly et al. [119] who compared embryonic mouse NSCs derived from the cortex and spinal cord, and found that although they shared similar properties when cultured, each NSC type retained some differences in gene expression. Such information is crucial for determining the most appropriate source of NSCs to repair particular regions of the CNS.

Regenerating oligodendrocytes could potentially reverse the demyelination and axonal degeneration in MS due to oligodendrocyte apoptosis, and it has been postulated that the multipotential neural precursor cells that reside within the SVZ could provide a source to replace lost oligodendrocytes following demyelination $[120,121]$. Thus, there is intense interest in understanding the endogenous mechanisms regulating their development. Recently, a network analysis using numerous normal human tissue samples identified a module of genes with coregulated expression in a tissue region that included the SVZ. Scrutiny of this model identified genes known to correlate with astrocytic expression and the authors surmised it to be a gene expression module for the adult subventricular neurogenic niche. This list may therefore include genes that are involved in NSC development or migration, however, not necessarily from a single-cell type as a number of cell types are presumed to be involved in the process.

\section{In vitro Models of Neural Injury}

Although it has been known for some time that protein synthesis occurs in dendrites [122], developing axons [123] and growth cones of adult sensory axons [124], it was not until recently that the diversity of the transcript populations within these subcellular compartments was realised.

Taylor et al. developed microfluidic technology for isolating axonally localised transcripts [125] and demonstrated for the first time the presence of $>300$ different types of mRNA transcripts localised in the axons of mature cortical axons [13]. They also used this approach to measure changes in the abundance of axonally localised transcripts following axotomy. They found that 2 days after axotomy, 866 transcripts (20\%) changed in abundance relative to naive axons, roughly equally distributed between increased and decreased transcripts. Gene ontology groups that were identified as increased included: cell differentiation, cell-cell signalling and secretion, all of which support axonal targeting and synaptic function. The presence of transcripts for translational machinery was notable for abundance in uninjured axons, however, it was not significantly changed following injury suggesting that translation rate per se is not altered. Furthermore, decreased localisation of transcripts involved in the electron transport chain suggests that injured neurons may re-grow in a more glycolytic mode [13].

It is interesting to compare these recent data with those of Willis et al. [14] who isolated axonal RNA from dissociated cultures of dorsal root ganglion neurons following 2 days of in vitro culture. These cultures had been preconditioned by sciatic nerve crush 7 days prior to culture. They identified $>200$ different transcripts as being present in the axonal RNA preparations and 91 of these transcripts were also localised to naive cortical axons [13], suggesting a high level of similarity between cortical and peripheral axons. However, since both these studies utilised an in vitro model, one must question whether this resembles the in vivo state of axons. Local synthesis of proteins occurs rapidly following axotomy, peaking at $1 \mathrm{~h}$ [126], suggesting localisation of mRNA ready for translation. Although Taylor et al. [13] showed that the cortical axonal RNA pool undergoes a rapid transition within 2 days of injury to supply protein synthesis demands, Willis et al. [14] showed that $>90 \%$ of the axonal RNA population is replaced over a 4-hour period of stimulation, thus revealing a highly dynamic process of axonal RNA localisation. Notably, Willis et al. [14] also demonstrated using qPCR that numerous transcripts respond dramatically in response to neurotrophins. 


\section{Conclusions and Future Directions}

Although microarray platforms have revealed daunting levels of complexity, they are incapable of surveying the true content and complexity of the transcriptome. High-throughput sequencing, however, is not constrained by current knowledge or prescriptive in design. Recent technological advances have enabled highthroughput sequencing analysis of single cells and has revealed yet more variation in the transcriptome. Singlecell mRNA-seq assay using ABI SOLiD sequencing on a single mouse blastomere identified $75 \%$ more transcripts $(5,270)$ than was detected by a parallel microarray using 80 pooled 4 -cell embryos [127]. In addition to detecting many more transcripts, this study also identified 1,753 new splice junctions. This is comparable to a recent highthroughput sequencing study on heterogenous tissue which detected up to 11,000 new splice junctions across 6 different tissues and estimated that 95\% of multiexon genes undergo alternative splicing [128]. High-throughput sequencing of undifferentiated embryonic stem cells also revealed a high level of novel transcript variants [129]. Transcriptome analysis using high-throughput sequencing of single cells comparing oocytes lacking components of miRNA processing machinery identified over 1,000 disregulated transcripts [127], demonstrating that miRNA plays an important and diverse role in regulation of the transcriptome. A recent novel finding is that a significant proportion of the transcriptome may also be made up of repeat elements [129]. Single-cell transcriptome analysis has recently been facilitated by the application of microfluidics to methodological problems of isolating cytoplasm for single-cell analysis [130, 131], resulting in the detection of 5,000 genes in a single neuron. Thus, although transcriptomic analysis using microarrays has enabled significant progress in our understanding of transcriptomic regulation in the CNS, it is clear that our current picture of transcriptional complexity is grossly simplified. The contribution of multiple splice variants, long ncRNA and miRNA, to the complexity of the CNS has barely been touched upon to date.

As microarray platforms have evolved to the level of whole genome analysis, the sophistication of analysis methods has similarly evolved. In particular, various types of network analysis are proving valuable in elucidating molecular signalling mechanisms from expression data. Critical molecules in biological pathways, such as kinases, may not exhibit expression changes at the transcriptional level, thus combining gene expression data with network data on interacting proteins and canonical pathway analysis is useful in identifying activated signalling pathways that would otherwise be missed or down weighted. Other network approaches analyse co-expressed genes which have similar profiles across a number of samples to identify 'modules' of related genes/ molecular components. Using this approach, Oldham et al. [3] showed that the cortical transcriptome is organised into a number of robust modules that are conserved among individuals. They went on to identify a number of interconnected transcriptional models representing distinct organelles, synapses, cell types and possibly a module characterising the adult subventricular neurogenic niche [3]. This type of analysis utilised 'differential network analysis' effectively normalising each sample and controlling for sources of variance arising from biological and technical factors. Therefore, this approach may assist in overcoming significant design problems encountered when using human CNS trauma samples. The organisation of the brain transcriptome in such a way may provide a foundation for identifying perturbation to modules as a result of disease or injury.

A network approach can also be used to capture functional differences in small networks of related genes. Palacios et al. [132] applied network analysis to a small starting set of only 20 genes known to be involved in the immune system. Expression profiling in $52 \mathrm{MS}$ patients and matched controls identified JAGGED1 (JAG1, ID 182) as an important regulator in T-cell activation whose activity was incompletely restored by interferon treatment and thus is a potential therapeutic target for autoimmune disease (MS) [132].

In addition to defining molecular pathways both within and between CNS cells, a detailed knowledge of the interconnecting pathways, neural circuits, is also lacking. We have very little understanding of how long-distance circuits involving multiple regions of the CNS orchestrate brain function, mental and behavioural outcomes. Disruption of this circuitry is a major cause of dysfunction following neural injury. An understanding of these pathways, 'the connectome', will lead to a better understanding of the impact of CNS injury on their disruption and may lead to improved therapies. The development of 'brainbow' mice allows the identification of the destination of an axon simply by a unique colour, thus making it possible to trace some long wiring connections in mammalian CNS [133]. These and other innovations lead to the exciting possibility that it may soon be possible to characterise the transcriptome of both a neuron and the cell it innervates in an in vivo model. 
Transcriptome analysis of neural injury has provided a glimpse of the complexity of the molecular signalling involved in the CNS response to injury, and yet a relatively small number of signalling pathways modulated in neural injury have been studied in any detail. Genomewide transcriptomic data sets have the capacity to reveal much more in spite of the growing realisation that measurements of transcript abundance reflect only one small mechanism of regulation. The problem of scale within the field is reflected in the range of experimental approaches commented upon in this review, ranging from subcellular RNA populations to GEP in heterogenous tissue regions. The analysis of cellular responses in isola- tion will never recapitulate biology, thus models of neural injury and repair require a systems approach capable of merging data from all scales. It is envisaged that such an approach could accommodate both spatial and temporal variations following neural injury as well as describe cell type-specific, cell-cell interaction and subcellular population responses. From the vast amounts of data generated by high-throughput technologies, analyses would define patterns or modules of molecular components and signalling instructions enabling researchers to describe biological and physiological responses in meaningful terms.

\section{References}

1 Sugino K, Hempel CM, Miller MN, Hattox AM, Shapiro P, Wu C, Huang ZJ, Nelson SB: Molecular taxonomy of major neuronal classes in the adult mouse forebrain. Nat Neurosci 2006;9:99-107.

-2 Roth RB, Hevezi P, Lee J, Willhite D, Lechner SM, Foster AC, Zlotnik A: Gene expression analyses reveal molecular relationships among 20 regions of the human CNS. Neurogenetics 2006;7:67-80.

-3 Oldham MC, Konopka G, Iwamoto K, Langfelder P, Kato T, Horvath S, Geschwind DH: Functional organization of the transcriptome in human brain. Nat Neurosci $2008 ; 11$ : 1271-1282.

-4 Bachoo RM, Kim RS, Ligon KL, Maher EA, Brennan C, Billings N, Chan S, Li C, Rowitch DH, Wong WH, DePinho RA: Molecular diversity of astrocytes with implications for neurological disorders. Proc Natl Acad Sci USA 2004;101:8384-8389.

5 Zhang Y, Ma C, Delohery T, Nasipak B, Foat BC, Bounoutas A, Bussemaker HJ, Kim SK, Chalfie M: Identification of genes expressed in C. elegans touch receptor neurons. Nature 2002;418:331-335.

- 6 Arlotta P, Molyneaux BJ, Chen J, Inoue J, Kominami R, Macklis JD: Neuronal subtype-specific genes that control corticospinal motor neuron development in vivo. Neuron 2005;45:207-221.

7 Marsh ED, Minarcik J, Campbell K, BrooksKayal AR, Golden JA: FACS-array gene expression analysis during early development of mouse telencephalic interneurons. Dev Neurobiol 2008;68:434-445.

-8 Cerda GA, Hargrave M, Lewis KE: RNA profiling of FAC-sorted neurons from the developing zebrafish spinal cord. Dev Dyn 2009; 238:150-161.
9 Lovatt D, Sonnewald U, Waagepetersen HS, Schousboe A, He W, Lin JH, Han X, Takano T, Wang S, Sim FJ, Goldman SA, Nedergaard $\mathrm{M}$ : The transcriptome and metabolic gene signature of protoplasmic astrocytes in the adult murine cortex. J Neurosci 2007;27: 12255-12266.

10 Cahoy JD, Emery B, Kaushal A, Foo LC, Zamanian JL, Christopherson KS, Xing Y, Lubischer JL, Krieg PA, Krupenko SA, Thompson WJ, Barres BA: A transcriptome database for astrocytes, neurons, and oligodendrocytes: a new resource for understanding brain development and function. J Neurosci 2008;28:264-278.

11 Luo L, Salunga RC, Guo H, Bittner A, Joy KC, Galindo JE, Xiao H, Rogers KE, Wan JS, Jackson MR, Erlander MG: Gene expression profiles of laser-captured adjacent neuronal subtypes. Nat Med 1999;5:117-122.

12 Rossner MJ, Hirrlinger J, Wichert SP, Boehm C, Newrzella D, Hiemisch H, Eisenhardt G, Stuenkel C, von Ahsen O, Nave KA: Global transcriptome analysis of genetically identified neurons in the adult cortex. J Neurosci 2006;26:9956-9966

13 Taylor AM, Berchtold NC, Perreau VM, Tu $\mathrm{CH}$, Li Jeon N, Cotman CW: Axonal mRNA in uninjured and regenerating cortical mammalian axons. J Neurosci 2009;29:46974707.

14 Willis DE, van Niekerk EA, Sasaki Y, Mesngon M, Merianda TT, Williams GG, Kendall M, Smith DS, Bassell GJ, Twiss JL: Extracellular stimuli specifically regulate localized levels of individual neuronal mRNAs. J Cell Biol 2007; 178:965-980.

15 Heiman M, Schaefer A, Gong S, Peterson JD, Day M, Ramsey KE, Suarez-Farinas M, Schwarz C, Stephan DA, Surmeier DJ, Greengard P, Heintz N: A translational profiling approach for the molecular characterization of CNS cell types. Cell 2008;135:738-748.
16 Heintz N: Gene expression nervous system atlas (GENSAT). Nat Neurosci 2004;7:483.

17 Doyle JP, DoughertyJD, Heiman M, Schmidt EF, Stevens TR, Ma G, Bupp S, Shrestha P, Shah RD, Doughty ML, Gong S, Greengard P, Heintz N: Application of a translational profiling approach for the comparative analysis of CNS cell types. Cell 2008; 135:749762.

18 Sibille E, Arango V, Joeyen-Waldorf J, Wang Y, Leman S, Surget A, Belzung C, Mann JJ, Lewis DA: Large-scale estimates of cellular origins of mRNAs: enhancing the yield of transcriptome analyses. J Neurosci Methods 2008;167:198-206.

19 Lin DM, Loveall B, Ewer J, Deitcher DL, Sucher NJ: Characterization of mRNA expression in single neurons. Methods $\mathrm{Mol}$ Biol 2007;399:133-152.

-20 Davis JE, Eberwine JH, Hinkle DA, Marciano PG, Meaney DF, McIntosh TK: Methodological considerations regarding single-cell gene expression profiling for brain injury. Neurochem Res 2004;29:1113-1121.

21 Kamme F, Salunga R, Yu J, Tran DT, Zhu J, Luo L, Bittner A, Guo HQ, Miller N, Wan J, Erlander M: Single-cell microarray analysis in hippocampus CA1: demonstration and validation of cellular heterogeneity. J Neurosci $2003 ; 23: 3607-3615$.

22 Hellmich HL, Garcia JM, Shimamura M, Shah SA, Avila MA, Uchida T, Parsley MA, Capra BA, Eidson KA, Kennedy DR, Winston JH, DeWitt DS, Prough DS: Traumatic brain injury and hemorrhagic hypotension suppress neuroprotective gene expression in injured hippocampal neurons. Anesthesiology 2005;102:806-814.

23 Subkhankulova T, Gilchrist MJ, Livesey FJ: Modelling and measuring single cell RNA expression levels find considerable transcriptional differences among phenotypically identical cells. BMC Genomics 2008;9:268. 
24 Du TG, Schmid M, Jansen RP: Why cells move messages: the biological functions of mRNA localization. Semin Cell Dev Biol 2007; 18:171-177.

25 Matsumoto M, Setou M, Inokuchi K: Transcriptome analysis reveals the population of dendritic RNAs and their redistribution by neural activity. Neurosci Res 2007;57:411423.

-26 Lugli G, Torvik VI, Larson J, Smalheiser NR: Expression of microRNAs and their precursors in synaptic fractions of adult mouse forebrain. J Neurochem 2008;106:650-661.

27 Suzuki T, Tian QB, Kuromitsu J, Kawai T, Endo S: Characterization of mRNA species that are associated with postsynaptic density fraction by gene chip microarray analysis. Neurosci Res 2007;57:61-85.

28 Pyhtila B, Zheng T, Lager PJ, Keene JD, Reedy MC, Nicchitta CV: Signal sequenceand translation-independent mRNA localization to the endoplasmic reticulum. RNA 2008;14:445-453.

29 Hesketh JE, Campbell GP, Whitelaw PF: C-myc mRNA in cytoskeletal-bound polysomes in fibroblasts. Biochem J 1991;274: 607-609.

30 Vedeler A, Hollas H: Annexin II is associated with mRNAs which may constitute a distinct subpopulation. Biochem J 2000;348:565572.

-31 Tenenbaum SA, Carson CC, Lager PJ, Keene JD: Identifying mRNA subsets in messenger ribonucleoprotein complexes by using cDNA arrays. Proc Natl Acad Sci USA 2000;97: 14085-14090.

- 32 Hogan DJ, Riordan DP, Gerber AP, Herschlag D, Brown PO: Diverse RNA-binding proteins interact with functionally related sets of RNAs, suggesting an extensive regulatory system. PLoS Biol 2008;6:e255.

- 33 Brown V, Jin P, Ceman S, Darnell JC, O'Donnell WT, Tenenbaum SA, Jin X, Feng Y, Wilkinson KD, Keene JD, Darnell RB, Warren ST: Microarray identification of FMRP-associated brain mRNAs and altered mRNA translational profiles in fragile $\mathrm{X}$ syndrome. Cell 2001;107:477-487.

- 34 Mercer TR, Dinger ME, Sunkin SM, Mehler MF, Mattick JS: Specific expression of long noncoding RNAs in the mouse brain. Proc Natl Acad Sci USA 2008;105:716-721.

- 35 Griffiths-Jones S, Saini HK, van Dongen S, Enright AJ: Mirbase: Tools for microRNA genomics. Nucleic Acids Res 2008;36:D154D158.

\36 Bak M, Silahtaroglu A, Moller M, Christensen M, Rath MF, Skryabin B, Tommerup $\mathrm{N}$, Kauppinen S: MicroRNA expression in the adult mouse central nervous system. RNA 2008; 14:432-444.

- 37 Trapp BD, Stys PK: Virtual hypoxia and chronic necrosis of demyelinated axons in multiple sclerosis. Lancet Neurol 2009;8: 280-291.

38 Korn T: Pathophysiology of multiple sclerosis. J Neurol 2008;255(suppl 6):2-6.
39 Lucchinetti C, Bruck W, Parisi J, Scheithauer B, Rodriguez M, Lassmann H: Heterogeneity of multiple sclerosis lesions: implications for the pathogenesis of demyelination. Ann Neurol 2000;47:707-717.

40 Barnett MH, Prineas JW: Relapsing and remitting multiple sclerosis: pathology of the newly forming lesion. Ann Neurol 2004;55: 458-468.

41 Dutta R, Trapp BD: Pathogenesis of axonal and neuronal damage in multiple sclerosis. Neurology 2007;68:S22-S31; discussion S43-S54.

42 Trapp BD, Nave KA: Multiple sclerosis: an immune or neurodegenerative disorder? Annu Rev Neurosci 2008;31:247-269.

43 Lassmann H, Bruck W, Lucchinetti CF: The immunopathology of multiple sclerosis: an overview. Brain Pathol 2007;17:210-218.

44 Baxter AG: The origin and application of experimental autoimmune encephalomyelitis. Nat Rev Immunol 2007;7:904-912.

-45 Taylor LC, Gilmore W, Matsushima GK: SJL mice exposed to cuprizone intoxication reveal strain and gender pattern differences in demyelination. Brain Pathol 2009;19:467479.

46 Irvine KA, Blakemore WF: Age increases axon loss associated with primary demyelination in cuprizone-induced demyelination in C57BL/6 mice. J Neuroimmunol 2006; 175:69-76

47 Comabella M, Martin R: Genomics in multiple sclerosis - current state and future directions. J Neuroimmunol 2007;187:1-8.

48 Baranzini SE, Bernard CC, Oksenberg JR: Modular transcriptional activity characterizes the initiation and progression of autoimmune encephalomyelitis. J Immunol 2005;174:7412-7422.

49 Carmody RJ, Hilliard B, Maguschak K, Chodosh LA, Chen YH: Genomic scale profiling of autoimmune inflammation in the central nervous system: the nervous response to inflammation. J Neuroimmunol 2002;133:95107.

50 Matejuk A, Dwyer J, Zamora A, Vandenbark AA, Offner $\mathrm{H}$ : Evaluation of the effects of 17beta-estradiol (17beta-e2) on gene expression in experimental autoimmune encephalomyelitis using DNA microarray. Endocrinology 2002;143:313-319.

51 Jelinsky SA, Miyashiro JS, Saraf KA, Tunkey C, Reddy P, Newcombe J, Oestreicher JL, Brown E, Trepicchio WL, Leonard JP, Marusic S: Exploiting genotypic differences to identify genes important for EAE development. J Neurol Sci 2005;239:81-93.

52 Mueller AM, Pedre X, Stempfl T, Kleiter I, Couillard-Despres S, Aigner L, Giegerich G, Steinbrecher A: Novel role for SLPI in MOGinduced EAE revealed by spinal cord expression analysis. J Neuroinflammation 2008; 20

Neurosignals 2009;17:311-327
3 Cudrici C, Ito T, Zafranskaia E, Weerth S, Rus V, Chen H, Niculescu F, Soloviova K, Tegla C, Gherman A, Raine CS, Shin ML, Rus H: Complement C5 regulates the expression of insulin-like growth factor binding proteins in chronic experimental allergic encephalomyelitis. J Neuroimmunol 2008;203: 94-103.

-54 Zeis T, Kinter J, Herrero-Herranz E, Weissert R, Schaeren-Wiemers N: Gene expression analysis of normal appearing brain tissue in an animal model for multiple sclerosis revealed grey matter alterations, but only minor white matter changes. J Neuroimmunol 2008;205:10-19.

-55 Lindberg RL, De Groot CJ, Certa U, Ravid R, Hoffmann F, Kappos L, Leppert D: Multiple sclerosis as a generalized CNS disease - comparative microarray analysis of normal appearing white matter and lesions in secondary progressive ms. J Neuroimmunol 2004; 152:154-167.

56 Zeis T, Graumann U, Reynolds R, SchaerenWiemers N: Normal-appearing white matter in multiple sclerosis is in a subtle balance between inflammation and neuroprotection. Brain 2008;131:288-303.

57 Matsushima GK, Morell P: The neurotoxicant, cuprizone, as a model to study demyelination and remyelination in the central nervous system. Brain Pathol 2001;11:107-116.

-58 Torkildsen O, Brunborg LA, Myhr KM, Bo L: The cuprizone model for demyelination. Acta Neurol Scand 2008;188(suppl):72-76.

-59 Wu QZ, Yang Q, Cate HS, Kemper D, Binder M, Wang HX, Fang K, Quick MJ, Marriott M, Kilpatrick TJ, Egan GF: MRI identification of the rostral-caudal pattern of pathology within the corpus callosum in the cuprizone mouse model. J Magn Reson Imaging 2008;27:446-453.

60 Hiremath MM, Saito Y, Knapp GW, Ting JP, Suzuki K, Matsushima GK: Microglial/macrophage accumulation during cuprizone-induced demyelination in C57BL/6 mice. J Neuroimmunol 1998;92:38-49.

61 Stangel M: Neuroprotection and neuroregeneration in multiple sclerosis. J Neurol 2008;255(suppl 6):77-81.

62 Jurevics H, Largent C, Hostettler J, Sammond DW, Matsushima GK, Kleindienst A, Toews AD, Morell P: Alterations in metabolism and gene expression in brain regions during cuprizone-induced demyelination and remyelination. J Neurochem 2002;82: 126-136.

63 Arnett HA, Wang Y, Matsushima GK, Suzuki K, Ting JP: Functional genomic analysis of remyelination reveals importance of inflammation in oligodendrocyte regeneration. J Neurosci 2003;23:9824-9832.

64 Plant SR, Wang Y, Vasseur S, Thrash JC, McMahon EJ, Bergstralh DT, Arnett HA, Miller SD, Carson MJ, Iovanna JL, Ting JP: Upregulation of the stress-associated gene $\mathrm{p} 8$ in mouse models of demyelination and in multiple sclerosis tissues. Glia 2006;53:529-537. 
-65 Li J, Ghiani CA, Kim JY, Liu A, Sandoval J, DeVellis J, Casaccia-Bonnefil P: Inhibition of p53 transcriptional activity: a potential target for future development of therapeutic strategies for primary demyelination. J Neurosci 2008;28:6118-6127.

66 Bramlett HM, Dietrich WD: Progressive damage after brain and spinal cord injury: pathomechanisms and treatment strategies. Prog Brain Res 2007;161:125-141.

67 Farkas O, Povlishock JT: Cellular and subcellular change evoked by diffuse traumatic brain injury: a complex web of change extending far beyond focal damage. Prog Brain Res 2007;161:43-59.

68 Morales DM, Marklund N, Lebold D, Thompson HJ, Pitkanen A, Maxwell WL, Longhi L, Laurer H, Maegele M, Neugebauer E, Graham DI, Stocchetti N, McIntosh TK: Experimental models of traumatic brain injury: do we really need to build a better mousetrap? Neuroscience 2005; 136:971989.

69 Onifer SM, Rabchevsky AG, Scheff SW: Rat models of traumatic spinal cord injury to assess motor recovery. ILAR J 2007;48:385395.

70 Sroga JM, Jones TB, Kigerl KA, McGaughy VM, Popovich PG: Rats and mice exhibit distinct inflammatory reactions after spinal cord injury. J Comp Neurol 2003;462:223240.

-71 Schmitt C, Miranpuri GS, Dhodda VK, Isaacson J, Vemuganti R, Resnick DK: Changes in spinal cord injury-induced gene expression in rat are strain-dependent. Spine J 2006;6:113-119.

72 Zheng B, Lee JK, Xie F: Genetic mouse models for studying inhibitors of spinal axon regeneration. Trends Neurosci 2006;29:640646.

73 Inman D, Guth L, Steward O: Genetic influences on secondary degeneration and wound healing following spinal cord injury in various strains of mice. J Comp Neurol 2002;451: 225-235.

74 Velardo MJ, Burger C, Williams PR, Baker HV, Lopez MC, Mareci TH, White TE, Muzyczka N, Reier PJ: Patterns of gene expression reveal a temporally orchestrated wound healing response in the injured spinal cord. J Neurosci 2004;24:8562-8576.

-75 Marciano PG, Eberwine JH, Ragupathi R, Saatman KE, Meaney DF, McIntosh TK: Expression profiling following traumatic brain injury: a review. Neurochem Res 2002;27: 1147-1155.

76 Dash PK, Kobori N, Moore AN: A molecular description of brain trauma pathophysiology using microarray technology: an overview. Neurochem Res 2004;29:1275-1286.

-77 von Gertten C, Flores Morales A, Holmin S, Mathiesen T, Nordqvist AC: Genomic responses in rat cerebral cortex after traumatic brain injury. BMC Neurosci 2005;6:69.
78 Kobori N, Clifton GL, Dash P: Altered expression of novel genes in the cerebral cortex following experimental brain injury. Brain Res Mol Brain Res 2002;104:148-158.

-79 Raghavendra Rao VL, Dhodda VK, Song G, Bowen KK, Dempsey RJ: Traumatic brain injury-induced acute gene expression changes in rat cerebral cortex identified by GeneChip analysis. J Neurosci Res 2003;71:208-219.

80 Rall JM, Matzilevich DA, Dash PK: Comparative analysis of mRNA levels in the frontal cortex and the hippocampus in the basal state and in response to experimental brain injury. Neuropathol Appl Neurobiol 2003; 29:118-131.

81 Matzilevich DA, Rall JM, Moore AN, Grill RJ, Dash PK: High-density microarray analysis of hippocampal gene expression following experimental brain injury. J Neurosci Res 2002;67:646-663.

82 Long Y, Zou L, Liu H, Lu H, Yuan X, Robertson CS, Yang K: Altered expression of randomly selected genes in mouse hippocampus after traumatic brain injury. J Neurosci Res 2003;71:710-720.

83 Yoshiya K, Tanaka H, Kasai K, Irisawa T, Shiozaki T, Sugimoto H: Profile of gene expression in the subventricular zone after traumatic brain injury. J Neurotrauma 2003; 20:1147-1162.

84 Li HH, Lee SM, Cai Y, Sutton RL, Hovda DA: Differential gene expression in hippocampus following experimental brain trauma reveals distinct features of moderate and severe injuries. J Neurotrauma 2004;21: 1141-1153.

85 Natale JE, Ahmed F, Cernak I, Stoica B, Faden AI: Gene expression profile changes are commonly modulated across models and species after traumatic brain injury. J Neurotrauma 2003;20:907-927.

86 Poulsen CB, Penkowa M, Borup R, Nielsen FC, Caceres M, Quintana A, Molinero A, Carrasco J, Giralt M, Hidalgo J: Brain response to traumatic brain injury in wildtype and interleukin- 6 knockout mice: a microarray analysis. J Neurochem 2005;92: 417-432.

87 Quintana A, Molinero A, Borup R, Nielsen FC, Campbell IL, Penkowa M, Hidalgo J: Effect of astrocyte-targeted production of IL- 6 on traumatic brain injury and its impact on the cortical transcriptome. Dev Neurobiol 2008;68:195-208.

88 Crawford FC, Wood M, Ferguson S, Mathura VS, Faza B, Wilson S, Fan T, O'Steen B, AitGhezala G, Hayes R, Mullan MJ: Genomic analysis of response to traumatic brain injury in a mouse model of Alzheimer's disease (APPsw). Brain Res 2007;1185:45-58.

89 Crawford F, Wood M, Ferguson S, Mathura V, Gupta P, Humphrey J, Mouzon B, Laporte V, Margenthaler E, O'Steen B, Hayes R, Roses A, Mullan M: Apolipoprotein E-genotype dependent hippocampal and cortical responses to traumatic brain injury. Neuroscience 2009;159:1349-1362.
\$0 Skibo GG, Lushnikova IV, Voronin KY, Dmitrieva O, Novikova T, Klementiev B, Vaudano E, Berezin VA, Bock E: A synthetic NCAM-derived peptide, FGL, protects hippocampal neurons from ischemic insult both in vitro and in vivo. Eur J Neurosci 2005;22:1589-1596.

-91 Neiiendam JL, Kohler LB, Christensen C, Li S, Pedersen MV, Ditlevsen DK, Kornum MK, Kiselyov VV, Berezin V, Bock E: An NCAM-derived FGF-receptor agonist, the FGL-peptide, induces neurite outgrowth and neuronal survival in primary rat neurons. J Neurochem 2004;91:920-935.

-92 Pedersen MV, Helweg-Larsen RB, Nielsen FC, Berezin V, Bock E, Penkowa M: The synthetic NCAM-derived peptide, FGL, modulates the transcriptional response to traumatic brain injury. Neurosci Lett 2008; 437:148-153.

93 Crack PJ, Gould J, Bye N, Ross S, Ali U, Habgood MD, Morganti-Kossman C, Saunders NR, Hertzog PJ: The genomic profile of the cerebral cortex after closed head injury in mice: effects of minocycline. J Neural Transm 2009;116:1-12.

-94 Redell JB, Liu Y, Dash PK: Traumatic brain injury alters expression of hippocampal microRNAs: potential regulators of multiple pathophysiological processes. J Neurosci Res 2009;87:1435-1448.

95 Aimone JB, Leasure JL, Perreau VM, Thallmair M: Spatial and temporal gene expression profiling of the contused rat spinal cord. Exp Neurol 2004;189:204-221.

-96 De Biase A, Knoblach SM, Di Giovanni S, Fan C, Molon A, Hoffman EP, Faden AI: Gene expression profiling of experimental traumatic spinal cord injury as a function of distance from impact site and injury severity. Physiol Genomics 2005;22:368-381.

-97 Szpara ML, Vranizan K, Tai YC, Goodman CS, Speed TP, Ngai J: Analysis of gene expression during neurite outgrowth and regeneration. BMC Neurosci 2007;8:100.

-98 Stam FJ, MacGillavry HD, Armstrong NJ, de Gunst MC, Zhang Y, van Kesteren RE, Smit AB, Verhaagen J: Identification of candidate transcriptional modulators involved in successful regeneration after nerve injury. Eur J Neurosci 2007;25:3629-3637.

-99 Bosse F, Hasenpusch-Theil K, Kury P, Muller HW: Gene expression profiling reveals that peripheral nerve regeneration is a consequence of both novel injury-dependent and reactivated developmental processes. J Neurochem 2006;96:1441-1457.

100 Lane MA, Truettner JS, Brunschwig JP, Gomez A, Bunge MB, Dietrich WD, Dziegielewska KM, Ek CJ, Vandeberg JL, Saunders NR: Age-related differences in the local cellular and molecular responses to injury in developing spinal cord of the opossum, Monodelphis domestica. Eur J Neurosci 2007;25:1725-1742. 
-101 Monaghan JR, Walker JA, Page RB, Putta S, 113 Obayashi S, Tabunoki H, Kim SU, Satoh JI: Beachy CK, Voss SR: Early gene expression during natural spinal cord regeneration in the salamander Ambystoma mexicanum. J Neurochem 2007;101:27-40.

- 102 Berchtold NC, Cribbs DH, Coleman PD, Rogers J, Head E, Kim R, Beach T, Miller C, Troncoso J, Trojanowski JQ, Zielke HR, Cotman CW: Gene expression changes in the course of normal brain aging are sexually dimorphic. Proc Natl Acad Sci USA 2008;105:15605-15610.

-103 Lock C, Hermans G, Pedotti R, Brendolan A, Schadt E, Garren H, Langer-Gould A, Strober S, Cannella B, Allard J, Klonowski P, Austin A, Lad N, Kaminski N, Galli SJ, Oksenberg JR, Raine CS, Heller R, Steinman L: Gene-microarray analysis of multiple sclerosis lesions yields new targets validated in autoimmune encephalomyelitis. Nat Med 2002;8:500-508.

104 Tajouri L, Mellick AS, Ashton KJ, Tannenberg AE, Nagra RM, Tourtellotte WW, Griffiths LR: Quantitative and qualitative changes in gene expression patterns characterize the activity of plaques in multiple sclerosis. Brain Res Mol Brain Res 2003; 119:170-183.

-105 Mycko MP, Papoian R, Boschert U, Raine CS, Selmaj KW: Microarray gene expression profiling of chronic active and inactive lesions in multiple sclerosis. Clin Neurol Neurosurg 2004;106:223-229.

- 106 Dutta R, McDonough J, Yin X, Peterson J, Chang A, Torres T, Gudz T, Macklin WB, Lewis DA, Fox RJ, Rudick R, Mirnics K, Trapp BD: Mitochondrial dysfunction as a cause of axonal degeneration in multiple sclerosis patients. Ann Neurol 2006;59: 478-489.

-107 Michael DB, Byers DM, Irwin LN: Gene expression following traumatic brain injury in humans: analysis by microarray. J Clin Neurosci 2005;12:284-290.

108 Einstein O, Ben-Hur T: The changing face of neural stem cell therapy in neurologic diseases. Arch Neurol 2008;65:452-456.

109 Vescovi AL, Snyder EY: Establishment and properties of neural stem cell clones: plasticity in vitro and in vivo. Brain Pathol 1999;9:569-598.

-110 Muller FJ, Snyder EY, Loring JF: Gene therapy: can neural stem cells deliver? Nat Rev Neurosci 2006;7:75-84

-111 Okano H, Sawamoto K: Neural stem cells: involvement in adult neurogenesis and CNS repair. Philos Trans R Soc Lond B Biol Sci 2008;363:2111-2122.

-112 Cai Y, Wu P, Ozen M, Yu Y, Wang J, Ittmann M, Liu M: Gene expression profiling and analysis of signaling pathways involved in priming and differentiation of human neural stem cells. Neuroscience 2006;138:133-148.
Gene expression profiling of human neura progenitor cells following the serum-induced astrocyte differentiation. Cell Mol Neurobiol 2009;29:423-438.

114 Wen T, Gu P, Minning TA, Wu Q, Liu M, Chen F, Liu H, Huang H: Microarray analysis of neural stem cell differentiation in the striatum of the fetal rat. Cell Mol Neurobiol 2002;22:407-416.

115 Karsten SL, Kudo LC, Jackson R, Sabatti C, Kornblum HI, Geschwind DH: Global analysis of gene expression in neural progenitors reveals specific cell-cycle, signaling, and metabolic networks. Dev Biol 2003;261:165-182.

116 Gurok U, Steinhoff C, Lipkowitz B, Ropers $\mathrm{HH}$, Scharff C, Nuber UA: Gene expression changes in the course of neural progenitor cell differentiation. J Neurosci 2004;24: 5982-6002.

-117 Wu P, Tarasenko YI, Gu Y, Huang LY, Coggeshall RE, Yu Y: Region-specific generation of cholinergic neurons from fetal human neural stem cells grafted in adult rat. Nat Neurosci 2002;5:1271-1278.

118 Williams C, Wirta V, Meletis K, Wikstrom L, Carlsson L, Frisen J, Lundeberg J: Catalog of gene expression in adult neural stem cells and their in vivo microenvironment. Exp Cell Res 2006;312:1798-1812.

119 Kelly TK, Karsten SL, Geschwind DH, Kornblum HI: Cell lineage and regional identity of cultured spinal cord neural stem cells and comparison to brain-derived neural stem cells. PLoS One 2009;4:e4213.

120 Nait-Oumesmar B, Decker L, Lachapelle F, Avellana-Adalid V, Bachelin C, Van Evercooren AB: Progenitor cells of the adult mouse subventricular zone proliferate, migrate and differentiate into oligodendrocytes after demyelination. Eur J Neurosci 1999;11:4357-4366.

121 Picard-Riera N, Decker L, Delarasse C, Goude K, Nait-Oumesmar B, Liblau R, Pham-Dinh D, Evercooren AB: Experimental autoimmune encephalomyelitis mobilizes neural progenitors from the subventricular zone to undergo oligodendrogenesis in adult mice. Proc Natl Acad Sci USA 2002;99:13211-13216.

122 Sutton MA, Schuman EM: Dendritic protein synthesis, synaptic plasticity, and memory. Cell 2006;127:49-58.

123 Campbell DS, Holt CE: Chemotropic responses of retinal growth cones mediated by rapid local protein synthesis and degradation. Neuron 2001;32:1013-1026.
124 Willis DE, Twiss JL: The evolving roles of axonally synthesized proteins in regeneration. Curr Opin Neurobiol 2006;16:111-118.

125 Taylor AM, Blurton-Jones M, Rhee SW, Cribbs DH, Cotman CW, Jeon NL: A microfluidic culture platform for CNS axonal injury, regeneration and transport. Nat Methods 2005;2:599-605.

$\checkmark 126$ Verma P, Chierzi S, Codd AM, Campbell DS, Meyer RL, Holt CE, Fawcett JW: Axonal protein synthesis and degradation are necessary for efficient growth cone regeneration. J Neurosci 2005;25:331-342.

- 127 Tang F, Barbacioru C, Wang Y, Nordman E, Lee C, Xu N, Wang X, Bodeau J, Tuch BB, Siddiqui A, Lao K, Surani MA: mRNA-Seq whole-transcriptome analysis of a single cell. Nat Methods 2009;6:377-382.

128 Pan Q, Shai O, Lee LJ, Frey BJ, Blencowe BJ: Deep surveying of alternative splicing complexity in the human transcriptome by high-throughput sequencing. Nat Genet 2008;40:1413-1415.

129 Cloonan N, Forrest AR, Kolle G, Gardiner BB, Faulkner GJ, Brown MK, Taylor DF, Steptoe AL, Wani S, Bethel G, Robertson AJ, Perkins AC, Bruce SJ, Lee CC, Ranade SS, Peckham HE, Manning JM, McKernan KJ, Grimmond SM: Stem cell transcriptome profiling via massive-scale mRNA sequencing. Nat Methods 2008;5:613-619.

130 Marcus JS, Anderson WF, Quake SR: Microfluidic single-cell mRNA isolation and analysis. Anal Chem 2006;78:3084-3089.

131 Bontoux N, Dauphinot L, Vitalis T, Studer V, Chen Y, Rossier J, Potier MC: Integrating whole transcriptome assays on a lab-on-achip for single cell gene profiling. Lab Chip 2008;8:443-450.

132 Palacios R, Goni J, Martinez-Forero I, Iranzo J, Sepulcre J, Melero I, Villoslada P: A network analysis of the human T-cell activation gene network identifies JAGGED1 as a therapeutic target for autoimmune diseases. PLoS One 2007;2:e1222.

133 Livet J, Weissman TA, Kang H, Draft RW, Lu J, Bennis RA, Sanes JR, Lichtman JW: Transgenic strategies for combinatorial expression of fluorescent proteins in the nervous system. Nature 2007;450:56-62.

134 Berchtold NC, Oliff HS, Isackson P, Cotman CW: Hippocampal BDNF mRNA shows a diurnal regulation, primarily in the exon III transcript. Brain Res Mol Brain Res 1999;71:11-22.

135 Simpson JE, Hosny O, Wharton SB, Heath PR, Holden H, Fernando MS, Matthews F, Forster G, O'Brien JT, Barber R, Kalaria RN, Brayne C, Shaw PJ, Lewis CE, Ince PG: Microarray RNA expression analysis of cerebral white matter lesions reveals changes in multiple functional pathways. Stroke 2009;40:369-375. 